26. Sowden A, Arblaster L. Community interventions for preventive smoking in young people. Cochrane database of systematic reviews 2000 www.cochrane.org.

27. Manee CL, Hemphill JC, Letran J. Screening clinics for the homeless: evaluating outcomes. J Community Health Nurs 1996; 13(3): 167-77.

28. Access Support and Evaluation Research Unit. Access to health care for homeless people: a guide to currently accepted practice. Melbourne: University of Melbourne, 1997.

29. Review of literature on early intervention and home visiting program evaluation Draft-Families First Framework. Sydney: Office of Children and Young People, NSW Cabinet Office, 2000.

30. NHS Centre for Reviews and Dissemination. Review of the effectiveness of health service interventions to reduce variations in health. York: University of York, 1995.

31. Macintyre S, Chalmers I, Horton R, Smith R. Using evidence to inform health policy: case study. BMJ 2001; 222-225.

32. Lee P, Rose V, Harris E, Bonney M. National Divisions Diabetes Program. Optional Module 1. Part A. Aboriginal and Torres Strait Islander Populations. Sydney: Centre for General Practice Integration Studies and Centre for Health Equity Training Research and Evaluation, 1999.

33. Oldenberg B, McGuffog ID, Turrell G. Socioeconomic determinants of health in Australia: policy responses and intervention options. MJA 2000; 172(10): 489-92.

34. Whitehead M. The concepts and principles of equity and health. Geneva: World Health Organization, Regional Office, 1990.

35. Browne G, Roberts J, Gefni A, Byrne C, Weir R, Majumdar $\mathrm{B}$, Watt $\mathrm{S}$. Economic evaluations of community based care: less from twelve studies in Ontario. Journal of Evaluation in Clinical Practice 1999; 5(4): 367-85.

36. Forrest C, Whelan EM. Primary care safety-net delivery sites in the United States. A comparison of community health centers, hospital outpatient departments and physicians' offices. JAMA 2000; 284: 2066-2083.

37. Wagner EH, Glascow RE, Davis C, Bonomi AE, Provost L, McCulloch D, Carver P, Sixta C. Quality improvement in chronic illness: a collaborative approach. Joint Commission Journal on Quality Improvement 2001; 27: 63-80. 即

\title{
CAN THE FAMILIES FIRST INITIATIVE CONTRIBUTE TO REDUCING HEALTH INEQUALITIES?
}

\section{Garth Alperstein}

Division of Population Health

Central Sydney Area Health Service

\section{Victor Nossar}

Department of Community Paediatrics

South Western Sydney Area Health Service

This article describes the ways in which Families Firsta coordinated strategy of the NSW Government that has increased the effectiveness of early intervention and prevention services in helping families to raise healthy and well adjusted children - can contribute to reducing health inequalities.

\section{CHILD HEALTH INEQUALITY TODAY}

Inequality of health outcomes continues to be a major (and potentially reversible) feature of the health of Australia's children. The health of children is particularly sensitive to their socioeconomic environment. This environment can diminish the potential of 'reactive' or 'clinical' services to reduce health inequalities in children.

In spite of this, there has been progress in reducing some health inequalities over the past century. In 1970, the gap in infant mortality between Aboriginal and non-Aboriginal children was approximately four-fold. In
1998 this gap had reduced to approximately three-fold, but there has been little change over the last decade. Almost every health indicator related to children and youth continues to reveal a significant gap between the Aboriginal and non-Aboriginal populations. ${ }^{1}$ However, in Australia, there is a dearth of health outcomes data for children and youth by other indicators of disadvantage such as family income, occupation of parent(s), and income distribution.

There are abundant data indicating the relationship between socioeconomic inequality and poor health outcomes; and of growing income inequality in Australia. $^{2}$ For example, the share of equivalent gross household income received by the bottom 10 per cent of Australians decreased from 7.44 per cent in 1986 to 7.35 per cent in 1996; and that received by the top 10 per cent increased from 13.7 per cent in 1986 to 14.96 per cent in 1996; also, there has been an increase in child poverty in Australia. ${ }^{3,4}$ Similar trends towards growing inequality have been even more clearly established between the developed and developing worlds. In the face of this, at best, unchanging income inequality - or, more probably, growing income inequality-how likely is it that the strategies underpinning Families First can reduce health and social inequalities? 
It is also worth recalling that serious health inequalities can persist (and even widen) in spite of the implementation of 'effective' interventions as these may produce improvements in the average rates of problems or diseases, but result in a widening of the gap between the upper and lower social strata. ${ }^{5,6,7}$

\section{WHAT IS FAMILIES FIRST?}

Families First is a coordinated strategy of the NSW Government to increase the effectiveness of early intervention and prevention services in helping families to raise healthy, well adjusted children. The NSW Government has committed \$54.2 million to implement the strategy in all areas of NSW over a four-year period. ${ }^{8}$

The implementation of Families First is the combined responsibility of a number of NSW government agencies (the area health services; the Department of Community Services; the Department of Ageing, Disability and Home Care; the Department of Education and Training; the Department of Housing; and the Department of Health) and non-government agencies funded by the NSW Government.

The main objectives of the Families First strategy are to:

- help children grow to their full potential; support parents in enhancing parenting skills and to have a sense of control over their lives; support those who are expecting or caring for babies, infants, and young children up to eight years of age; and assist families who require extra support;

- help communities build and sustain networks to support families through strengthening the connections between communities and families.

These objectives will be met through a combination of universal and targeted services:

- a universal home visiting program that also concentrates services to vulnerable and disadvantaged families;

- extra support to families with specific health and social problems; for example: mental health, substance abuse, social isolation, financial stress, homelessness, etc;

- a coordinated network of services linking all sectors relevant to the health and social wellbeing of families with young children;

- community capacity building and community development programs targeting disadvantaged communities, using the Schools as Community Centres and other models.

These strategies are supported by research indicating that early intervention services and community capacity building programs can produce a sustained improvement in children's health, education, and welfare..$^{9,10,11,12}$ There is also evidence that early intervention services have the greatest impact when they are capable of addressing a broad range of issues and are provided as part of a coordinated network. ${ }^{13,14}$

\section{THE LINKAGES BETWEEN FAMILIES FIRST AND THE PROBLEM OF INEQUALITY}

How much potential do the strategies underpinning Families First have for reducing inequalities of health outcomes? Which particular components of Families First are more likely to be effective?

Two of the overseas programs whose design underpin Families First (the Prenatal-Early Infancy Project and the High-Scope Perry Preschool Project) have demonstrated that the greatest benefit accrues to children in families at greatest social disadvantage. ${ }^{9,10}$ These findings suggest significantly better prospects for the reduction of health inequalities through Families First than through conventional service-based initiatives. ${ }^{9,15}$

A number of randomised controlled trials of home visiting programs delivered to disadvantaged and vulnerable families predominantly in the USA, ${ }^{16}$ but also in Australia, ${ }^{17}$ have demonstrated positive health and social outcomes for children and mothers. These have included:

- reduced rates of smoking in pregnancy, hypertension of pregnancy, low birth-weight, preterm babies, child abuse, accidental injury, behavioural problems, high risk behaviours among adolescents, running away from home, delinquency, and mothers' dependency on welfare;

- increased rates of breastfeeding and immunisation, and better use of health services.

The data are less clear regarding the impact of a universally offered home visiting program with a concentration of services on the vulnerable and disadvantaged.

Intuitively, one would expect even better outcomes because the whole socioeconomic gradient is addressed and thereby potentially influencing greater numbers of children and families. However, there is some evidence that indicates that one home visit may be of little or no benefit. ${ }^{18}$ There are also data indicating that the proportion of children living in relative poverty in the USA is greater; ${ }^{19}$ and, in general, outcomes for the disadvantaged in the USA are worse than in Australia. Therefore, the degree of benefit observed in home visiting studies in the USA may be attenuated in the less-extreme Australian context. Although the funding currently provided to implement Families First is significant, it may yet prove insufficient to provide the levels of home visiting required to make a difference. For example, the Central Sydney Area Health Service would require an additional recurrent allocation of $\$ 1.2$ million per year to implement a universal home visiting program to the level indicated by effective programs, 
with resources focused on vulnerable and disadvantaged families.

Joint planning of services and preventative programs, which have been very successful in the Central Sydney Area Health Service as a means of addressing health inequities, has also not formally been evaluated. However, since health outcomes have multiple determinants, and approximately 70 per cent of which are not related to traditional health services,${ }^{20}$ the potential to further reduce health inequities is significant through joint planning with housing, education and community services, and other relevant agencies, including non-government agencies.

There is indirect evidence that community capacity building, and improving levels of social capital, have the potential to significantly improve not only child health outcomes but also adult health outcomes. There is a strong association between levels of social capital and total mortality rates; infant mortality rates; and deaths from cardiovascular disease, stroke, cancer, and homicide. ${ }^{21,22}$ Improving children's and young people's perception of connectedness with their family and schools has also been demonstrated to be associated with reduced risk taking behaviours and better mental health outcomes among adolescents. ${ }^{23}$

\section{POTENTIAL CONTRIBUTION OF FAMILIES FIRST TO REDUCING HEALTH INEQUALITIES}

There is a growing body of evidence about the relative contributions of healthcare services, and of social and economic determinants of health, to measures of health outcome (such as mortality rates). It indicates that the contributions may be different at different ages, with socioeconomic factors having a greater effect at younger ages. $^{24,25}$

Considering the importance of programs that address social and economic determinants to population health outcomes in children, Families First has the potential to significantly affect brain development in the early years of childrens' lives. Home visiting has been shown to decrease smoking rates in pregnancy in disadvantaged women; decrease rates of low birth-weight and preterm babies; increase rates of breastfeeding and the duration of breastfeeding; and improve education outcomes. ${ }^{9,15}$ Provision of books, reading support programs, and transition to school programs for disadvantaged children, have been shown to improve readiness to start school. ${ }^{26,27}$ Community capacity building programs such as the Schools as Community Centres program have improved social capital and empowered families in disadvantaged communities. ${ }^{28}$ Taken together, these kinds of strategieswhich form the basis of Families First - have the potential to start to break the cycle of poverty, vulnerability, and disadvantage for this cohort of children and their families; and to begin to reduce health inequalities.
There is also compelling evidence that cognitive function in adulthood is dependent on parents' socioeconomic circumstances (and parents' level of education). ${ }^{29}$ This suggests that the health, developmental, and social benefits of the strategies underpinning Families First are likely to extend into adulthood-something confirmed in some studies. ${ }^{9,10}$

\section{POTENTIAL LIMITATIONS OF FAMILIES FIRST}

There are a number of possible risks to the likelihood that Families First will achieve improvements in health outcomes and reductions in health inequalities.

'Shifting attention away from the population distribution of health, health inequalities, to the health of the poorest groups in society, health poverty, and to conditions that the poor tend to suffer from in isolation of the circumstances in which those conditions are suffered' has not been shown to have had any beneficial impact on existing health inequalities. ${ }^{30}$

Nor is it clear how much the socioeconomic distribution of risk factors explains the observed health inequalities, making it risky to base efforts to reduce heath inequities on strategies that focus on risk factors. ${ }^{30,31,32}$

If Families First focuses on strategies providing 'reactive' services to 'high- risk' families or individuals, rather than providing population-based preventative interventions, there can be little confidence from the evidence that the anticipated improvements in population-level child health outcomes will be achieved. ${ }^{33,34}$

It is unclear from the evidence that targeting of services, such as the selection of geographically disadvantaged areas for community capacity building programs, will reduce existing health inequalities. Research from Glasgow, Scotland, concluded that selective targeting of resources on an area basis would miss more deprived people than it would include. ${ }^{35}$ Such an analysis has not been done in NSW, but it is probable the same would apply. Furthermore, other determinants of health can all negate the potential benefits of Families First. These include: a world recession, or war; government policies that continue to contribute to widening the economic and social gap (such as retrogressive taxation and support of the privatisation of education and health systems); job insecurity; inappropriate design of public housing, which contributes to further erosion of social capital; tolerance by government and the community of discrimination and marginalisation based on gender, race, religion, and class; support of inequity as inevitable; and sustainability of the environment.

\section{CONCLUSION}

Families First has the potential to reduce inequalities in health outcomes in children, and so to contribute to breaking the cycle of poverty for disadvantaged children, 
their families, and the adults they will become. However, this initiative cannot succeed on its own; it must be supported by other political, economic, and social developments.

\section{REFERENCES}

1. Moon L, Rahman N, Bhatia K. Australia's Children. Their health and well being. Canberra: Australian Institute of Health and Welfare, 1998.

2. Harding A. Trends in income inequality in the 1990s. Canberra: National Centre for Social and Economic Modelling, University of Canberra, August, 2001.

3. Sullivan EA, Raman S, Nossar V. Surveillance of child poverty in Australia using National Health Surveys 19831995. Proceedings of the CDC Maternal, Infant and Child Health Epidemiology Workshop, December 1999. Atlanta, GA. Unpublished.

4. Harding A, Szukalska A. A portrait of child poverty in Australia in 1995-96. Canberra: National Centre for Social and Economic Modelling, University of Canberra, 1998.

5. Daltveit AK, Oyen N, Skjaerven R, Irgens LM. The epidemic of SIDS in Norway 1967-93: changing effects of risk factors. Arch Dis Child 1997; 77: 23-27.

6. Alvarez-Dardet C, Montahud C, Ruiz MT. The widening social class gap of preventative health behaviours in Spain. European J Pub Health 2001; 11: 225-6.

7. Saraiya M, Serbanescu F, Rochat R, Berg CJ, Iyasu S, Gargiullo PM. Trends and predictors of infant sleep positions in Georgia, 1990-1995. Pediatrics 1998; 102(3): E33.

8. The Office of Children and Young People. Families FirstAn initiative of the NSW Government: A Support Network for Families Raising Children. Sydney: NSW Cabinet Office, April 1999.

9. Olds DL, Eckenrode J, Henderson CR, et al. Long term effects on home visitation on life course and child abuse and neglect: fifteen year follow up of a randomized trial. JAMA 1997; 278: 637-643.

10. Schweinhart LJ, Barnes HV, Weikart DP. Significant Benefits: The High/Scope Perry Pre-school study through age 27. Yipsilanti, MI: High-Scope Press, 1993.

11. Weatherburn D, Lind B. Social and economic stress, child neglect and juvenile delinquency. Sydney: NSW Bureau of Crime Statistics and Research, NSW Attorney General's Department, 1997.

12. Cant R. Inter-agency School as Community Centre Pilot Project. Evaluation Report, Social Systems and Evaluation. Sydney: NSW Department of School Education, 1997.

13. Loeber R and Farrington D. Never too early, never too late: Risk factors and successful interventions for serious and violent juvenile offenders. Studies on Crime and Crime Prevention 1998; 7(1).

14. Wilson C and Dunne E. Factors identifiable from longitudinal child development studies in the prenatal and early childhood years (0-5) which lead to disadvantage in later life. Adelaide: The Office for Families and Children, 1998.

15. Olds DL, Kitzman H. Review of research on home visiting for pregnant women and parents of young children. The Future of Children 1993; 3(3).
16. Roberts I, Kramer MS, Suissa S. Does home visiting prevent childhood injury? A systematic review of randomized controlled trials. BMJ 312;29-33.

17. Webster H, Armstrong K. Home visiting to urban indigenous families with newborns: implementation and evaluation of pilot program. Presentation of abstract. Royal Australasian College of Physicians Annual Scientific Meeting, Sydney, May, 2001.

18. King WJ, Klassen T, LeBlanc J, et al. The effectiveness of a home visit to prevent childhood injury. Pediatrics 2001; 108: 382-388.

19. Innocenti Report Card No 1. A league table of child poverty in rich nations. Florence: UNICEF Innocenti Research Centre, 2000.

20. Evidence from the Health Development Agency, National Health Service. Health Committee Publications. HealthSecond Report. London: British House of Commons, 2001. ISBN 0102210012.

21. Kawachi I, Kennedy BP, Lochner SM, Prothrow-Stith D. Social capital, income inequality and mortality. Am J Public Health 1997; 87: 1491-1498.

22. Kennedy BP, Kawachi I, Prothrow-Stith D, Lochner SM, Gupta V. Social capital, income inequality and firearm violent crime. Soc Sci Med. 1998; 47: 7-17.

23. Resnick MD, Bearman PS, Blum RW et al. Protecting adolescents from harm: findings from the National Longitudinal Study on Adolescent Health. JAMA 1997; 278 : 823-832.

24. Or Z. Exploring the effects of health care on mortality across OECD countries. Labour Market and Social PolicyOccasional Papers No. 46. Paris: OECD, January 2001.

25. Lynch J, Davey Smith G, Hillemeier M, Shaw M et al. Income inequality, the psychosocial environment, and health: comparisons of wealthy nations. Lancet 2001; 358: 194200.

26. Golova N, Alario AJ, Vivier PM, Rodriguez M et al. Literacy promotion for Hispanic families in a primary care setting: A randomized, controlled trial. Pediatrics 1999; 103: 993-997.

27. Scarborough HS, Dobrich W, Hager M. Preschool literacy experience and later reading achievement. J Learn Disabil 1991; 24: 508-11.

28. Wraith C, Murphy E. Working together to support children and families in disadvantaged communities. NSW Public Health Bulletin 1998; 9: 131-133.

29. Kaplan GA, Turrell G, Lynch JW, Everson SA et al. Childhood socio-economic position and cognitive function in adulthood. Int J Epidemiol 2001; 30: 256-63.

30. Birch S. Commentary: Social inequalities in health, social epidemiology and social value. Int J Epidemiol 2001; 30: 294-296.

31. Blane D. Commentary: Socioeconomic health differentials. Int J Epidemiol. 2001; 30: 292-293.

32. Najman J.M. Commentary: General or cause — specific factors in explanations of class inequalities in health. Int J Epidemiol. 2001; 30: 296-297.

33. Marmot M. Economic and social determinants of disease. Bulletin of the World Health Organization 2001; 79: 988989.

34. Rose G. Sick individuals and sick populations. Int J Epidemiol 1985; 14: 32-38.

35. McLoone P. Targeting deprived area within small areas in Scotland: population study. $B M J 2001 ; 323: 374-375$. 